\title{
Study on the Manufacture and Feature of the Crushed Product of Acidic Treated Soybean Residue
}

\author{
KwangChol Oh${ }^{1}$, SongLok Uh ${ }^{2}$, BokShil Kim ${ }^{1}$, NamChol Choe ${ }^{1}$, YongChol Won ${ }^{1}$, UnSuk Guak ${ }^{1}$, SongIl Pak ${ }^{1}$ \\ 'Pyongyang Technology College of Food and Commodity, Pyongyang, Democratic People's Republic of Korea \\ ${ }^{2}$ Pyongyang JangCholGu University of Commerce, Pyongyang, Democratic People's Republic of Korea
}

\begin{abstract}
Article Info

Volume 8 Issue 1

Page Number: 137-146

Publication Issue :

January-February-2021

Article History

Because soybean residue contains a large amount of carbohydrate, protein, fiber, fat and so on, people's interest on soybean residue is increasing day by day, in order to use soybean residue in various food industry research is carried out widely. In this, through the method of extracting water-soluble soybean polysaccharides in the soybean residue that it is rich and the method of destroying the structure of SR, the conditions of improving the physical properties of SR is determined and the research for testing its properties is done. Firstly, the method and experiment design for extract water-soluble soybean polysaccharides is determined scientifically. Secondly, in order to improve the physical properties of SR, the optimal method of solution and treatment to destroying the structure of SR is selected scientifically. Through various experiment is carried out, that the best solution to destroying the structure of SR is the diluted solution of $\mathrm{HCl}$ is determined scientifically. The optimal treatment condition to improve the physical properties of SR is $0.04 \mathrm{M}$ of hydrochloric acid concentration, $70^{\circ} \mathrm{C}$ of temperature and 3 hours of time. The SR treated in this condition showed good powdering and the crushed products were very high in dispersion, emulsification stability and oil absorbed force.
\end{abstract}

Accepted : 01 Feb 2021

Published : 06 Feb 2021
Keywords : SR (Soybean Residue), Acid treatment, SSPS of SR, Extraction, Viscosity

\section{INTRODUCTION}

Because soybean has rich nutrient component that protein, fiber, fat and carbohydrate and so on, people's need level for the bean food is high, then which has led to the increase in the amount of SR, the by-products. Specially, a lot of scientist have a growing interest in SR, because carbohydrate is rich in it. Firstly the study on water-soluble polysaccharides (SSPS) was carried. Soybean processing products generally produce 30\%-35\% soybean residue (SR), which is prone to spoilage due to its high moisture content. It is often used as fodder or discarded, resulting in waste. The main component of SR is soluble soybean polysaccharides in the cell wall of its cotyledon, here is $30 \%$ of SSPS [1]. SSPS is a kind of acidic polysaccharides and the main component is galactose, arabinose, rhamnose(inositol), 
fucose(monosaccaride as hexose deoxysaccaride) and xylose and so on, these are native functional component that have different biological activity, therefore to improve the quality and processable property of foods and inhibite the fatty oxidation and stabilize the protein of acidic beverage, and the emulsion can be used as food ingredients, has extensive application prospect in the food. It also has certain effects in antioxidant, antibacterial, antiviral and immune regulation $[1,2]$.Despite its rich nutrient component, the SR are used only in some certain limited fields as it is hard of digestion, has big grain size and decreases the viscosity of other raw materials in the food stuff. Secondly a lot of studies have been carried out to widely introduce the SR into the foodstuff, and the method of adding various mucilage after fine grinding of SR[3], the method of zymolysis $[4,5]$, the method of bacterial treatment[6] have been established. Adding viscosity improved agent to the bean curd dreg increases the cost price of the product but not the digestibility of the bean curd dreg itself. Improving its physical properties by adding some germs also has some disadvantages, like the limitation in its usage for the special taste and smell caused by fermentate and the difficulty in control and operation of the germ. Many researchers isolated SSPS from SR and studied the utilization of SSPS as food additives. Soybean polysaccharides are traditionally extracted by hot water extraction, the method has low yield, its operation time is long and energy consumption is lots. In recent years, the extraction method of ultrasonic, microwave and other have been applied to the extraction of polysaccharides $[7,8]$. The two methods are simple to operate and can greatly shorten the extraction time, but cannot meet the needs of production well. In this study, the condition for improving the physical properties of the SR by extracting the SSPS of the SR and destroying its tissue structure was identified and the results of its feature were given.

\section{METHODS AND MATERIAL}

\subsection{MATERIALS}

(1) Materials

20g Soybean residue or SR with Particle size $474 \mu \mathrm{m}$.

(2) Reagents

SDS(sodium dodecyl sulfuric ) $100 \mathrm{~g},\left(\mathrm{NH}_{4}\right)_{2} \mathrm{C}_{2} \mathrm{O}_{4} 500$

$\mathrm{mL}, \mathrm{NaOH} 500 \mathrm{~mL}, \mathrm{HCl} 500 \mathrm{~mL}$, Sucrose fatty acid est er(HLB) 20g.

(3) Instruments

PHC-3C type $\mathrm{pH}$ meter;

NDJ- 8S type Rotary drum viscometer;

TGL 20M type centrifuge;

DZKW-S4 type Electric hot tub;

KA RW 20 type Agitator;

FW100 type High speed universal crusher;

$721 \mathrm{E}$ type Visible photometer;

L403 type Electronic balance.

(4) Period for experiment

From June 2020 to December 2020, an experiment was conducted at Northeast Agricultural University of China.

\subsection{Method}

\section{(1) Chemical composition of SR}

Crude protein was quantitated with kfeldahl method [9]; crude fat, Soxhlet extract method [10]; ash, ashing method [11]. Saccharide was measured: first quantitat e crud fiber $[12,13]$, and subtract crude protein, crude fat, ash and crude fiber from 100.

\section{(2) Extraction rate}

First extract upper liquid after centrifugation of SR fo r $20 \mathrm{~min}$ in 3500r/min, add 10 times of water, measur e the dried cake that has be precipitated after another centrifugation, and calculate using the following equa tion.

Extractability $=\frac{\left(M_{1}-M_{2}\right)}{M_{1}} \times 100 \%$

Where $M_{1}$; Mass of bean curd dregs sample,

$M_{2}$; Mass of the cake 
The extractability of sugar was calculated with phenol-sulfuric acid method [ 14 ] and the extractability of protein with kjeldahl method[9]. The extractability of the polymer component is 4 times $95 \%$ ethanol (V/V) added to the separation solution, dried the precipitate, weighed the percentage of the dry sample.

\section{(3) Viscosity}

The viscosity of the sample was measure at $17.0 \mathrm{~s}^{-1}$ of shear rate and $25^{\circ} \mathrm{C}$ of the temperature with.

$\tau=Z \times \alpha, 10^{-1} \mathrm{~Pa}$
$D_{r f}=D_{r} \times v / 50, \mathrm{~S}^{-1}$

Where $Z, \alpha$ : the range of shearing stress and gauge value of the indicator

$D_{\text {rf, }} D_{r}$ : Shear velocity in $50 \mathrm{~Hz}$ and shear velocity amended with a frequency just when measuring per second.

$\mathrm{v}$ : the frequency at the time of measurement

\section{(4) Dispersion stability-(DS)}

Put dispersed mother liquid in the $100 \mathrm{~mL}$ measuring cylinder, leave it for 30 minutes at $20^{\circ} \mathrm{C}$ and calculate with percentage of the whole volume of the sample li quid nad the down-volume of the separated part.

\section{(5) Emulsification stability - (ES)}

Put in the oil to be the $35 \%$ of the sample and makee mulsifying liquid after homogeneity for 5 minutes at 5 000r/min.

Put the emulsifying liquid in the $25 \mathrm{~mL}$ centrifugal tu be with scale mark on it, centrifugate it for 5 minutes at and calculate E.S. with following equation.

$$
E, S=\frac{V_{1}}{V_{2}} \times 100, \%
$$

Where $V_{1}$; volume of emusificated layer after centrifugation

$V_{2}$; volume of emusificated layer before centrifugation
(6) Water and oil absorbing capacity

Water absorbing capacity was calculated as follows; fi rst add $40 \mathrm{~mL}$ of distilled water to two grams of sample (dry material), treat in in the given condition, centrif ugate for 10 minutes at, remove upper liquid, measur e the mass of precipitate and the calculate with the fol lowing equation.

$$
\begin{gathered}
\text { Water absorbing capacity }=\frac{W_{1}-W_{2}}{W_{2}}, \text { Water }(\mathrm{g}) / \\
\text { Sample }(\mathrm{g})
\end{gathered}
$$

Where $W_{1}$; mass of deposit (g),

$W_{2}$; mass of used reagent $(\mathrm{g})$

The same method is applied for the case of oil and emulsifying liquid except that maize oil and emulsifying liquid were used instead of water. As for the emulsifiers for the manufacture of emulsifying liquid, sucrose fatty acid ester was used. (Density of emulsifiers $0.5 \%$ )

\section{(7) Grinding coefficient}

$500 \mathrm{~mL}$ of water was added to the crushed product of SR and it was passed through 60-mexh screen after sh aking it well.

The cake caught by the sieve was washed three times with $500 \mathrm{~mL}$ of water and the crushing rate was calcu lated with following equation.

$$
\text { Grinding coefficient }=\frac{A-B}{A} \times 100, \%
$$

Where A, B; the mass cake failed to go through the sieve before and after crushing. (dry material), $g$

\section{RESULTS}

\subsection{Composite of the SR}

The results of analyzing the chemical composite of the SR is shown in table 1. 
Table 1. Chemical composite of the SR \%

\begin{tabular}{|c|c|c|c|c|c|}
\hline Section & Water & Coarse protein & Coarse oil & Ash & Coarsefiber \\
\hline Naterial & $82.51 \pm 0.24^{\mathrm{a}}$ & $4.10 \pm 0.04^{\mathrm{b}}$ & $2.24 \pm 0.02^{\mathrm{b}}$ & $0.54 \pm 0.03^{\mathrm{b}}$ & $10.57 \pm 0.57^{\mathrm{b}}$ \\
\hline Dried SR & $6.96 \pm 0.48^{\mathrm{b}}$ & $21.35 \pm 0.09^{\mathrm{a}}$ & $10.08 \pm 0.04^{\mathrm{a}}$ & $3.74 \pm 0.01^{\mathrm{a}}$ & $57.87 \pm 0.43^{\mathrm{a}}$ \\
\hline
\end{tabular}

※ Data with different small letters $(\mathrm{a} \sim \mathrm{b})$ in a column are significantly different at $p<0.05$ by Duncan's multiple range test.

As shown in Table 1, SR contain $21.35 \%$ protein, $57.87 \%$ carbohydrates in dry material, that is carbohydrates (polysaccharide + crude fiber) account for more than $60 \%$ of the SR. The experiment results of Table 1 shows th at an effective extraction of the great quantity of SSPS contained in SR can be used as the quality-improver of $t$ he food stuff.

\subsection{Manufacture of crushed product of SR acid treatment}

(1) Selection of medium

First the features related to physical property improvement of SR by using the dodecyl sulfuric sodium solvent that dissembles the sugar-protein complex, the (NH4) ${ }_{2} \mathrm{C}_{2} \mathrm{O}_{4}$ solvent, that dissembles the complex of the SSPS th at is combined with multiply cation (like $\mathrm{Ca}, \mathrm{Mg}$ ) and protein, $\mathrm{NaOH}$ solvent, that dissembles the complex of $\mathrm{pr}$ otein of a strong hydrogen bond and polysaccharide, and $\mathrm{HCl}$ solvent that dissembles the hydrogen complex wi th the multiply cation and the glycoside bond of SSPS in the plant organism of the previous studies.

Table 2. Treatment effects of the SR treated in various media

\begin{tabular}{|c|c|c|c|c|c|c|}
\hline Efficiency & \multicolumn{4}{|c|}{ Separating efficiency } & \multicolumn{2}{|c|}{ Grinding efficiency } \\
\hline $\begin{array}{l}\quad \text { Characteristics } \\
\text { Processing } \\
\text { medium }\end{array}$ & $\begin{array}{c}\text { Separation } \\
\text { coefficient } \\
\%\end{array}$ & $\begin{array}{c}\text { Protein } \\
\text { separation } \\
\text { coefficient } \\
\%\end{array}$ & $\begin{array}{c}\text { Sugar } \\
\text { separation co } \\
\text { efficient } \\
\%\end{array}$ & $\begin{array}{l}\begin{array}{c}\text { Viscosity } \\
\text { of }\end{array} \\
\text { separating liq } \\
\text { uid } \\
\eta \cdot 10^{3}, \mathrm{~Pa} \cdot \mathrm{S}\end{array}$ & $\begin{array}{c}\text { Grinding } \\
\text { coefficient } \\
\%\end{array}$ & $\begin{array}{l}\text { Viscosity of } \\
\text { grinding } \\
\text { material } \\
\mathrm{Pa} \cdot \mathrm{S}\end{array}$ \\
\hline $0.5 \%\left(\mathrm{NH}_{4}\right)_{2} \mathrm{C}_{2} \mathrm{O}_{4}^{*}$ & $29.79 \pm 0.23^{c}$ & $9.35 \pm 0.45^{\mathrm{d}}$ & $15.83 \pm 0.46^{\mathrm{d}}$ & $6.5 \pm 0.12^{c}$ & $29.4+0.65^{c}$ & $0.77 \pm 0.41^{\mathrm{d}}$ \\
\hline $0.1 \mathrm{M} \mathrm{HCl}^{*}$ & $46.50 \pm 0.41^{\mathrm{a}}$ & $15.14+0.34^{a}$ & $26.46 \pm 0.48^{\mathrm{a}}$ & $10.8 \pm 0.14^{a}$ & $78.6 \pm 0.73^{b}$ & $1.16 \pm 0.32^{\mathrm{b}}$ \\
\hline $0.1 \mathrm{M} \mathrm{NaOH}^{*}$ & $39.81 \pm 0.52^{b}$ & $15.67 \pm 0.21^{\mathrm{b}}$ & $19.52+0.35^{b}$ & $8.3 \pm 0.15^{b c}$ & $64.8 \pm 0.57^{\mathrm{a}}$ & $0.98 \pm 0.46^{a}$ \\
\hline $0.5 \%$ SDS & $\begin{array}{c}29.12+0.32^{b} \\
c\end{array}$ & $14.28 \pm 0.53$ & $10.69 \pm 0.46^{c}$ & $5.9 \pm 0.17^{\mathrm{b}}$ & $23.7 \pm 0.68 \mathrm{bc}$ & $0.71 \pm 0.56^{c}$ \\
\hline
\end{tabular}

※ Data with different small letters ( $\mathrm{a}^{\sim} \mathrm{d}$ ) in a column are significantly different at $p<0.05$ by Duncan’s multiple range test.

As shown in the table 2, grinding coefficient and viscosity are different depending on that in which medium SR is processed, especially grinding coefficient and viscosity of $\mathrm{HCl}$ and $\mathrm{NaOH}$ tube are very high. The experimen 
$\mathrm{t}$ results in Table 2 shows that during the treatment of $\mathrm{HCl}$ and $\mathrm{NaOH}$ the tissue structure of the SR is damaged, which allows the extraction of some of its composites including polysaccharides and protein, and at the same ti me they are crushed into smaller pieces by the external mechanical knock, which increases the viscosity of the crushed product. As shown in Table 2, the treatment media with high extraction rate of protein and sugar are $\mathrm{NaOH}$ or $\mathrm{HCl}$ and $\mathrm{HCl}$ not only has high sugar extraction rate but also high viscosity of separation liquid. So w hen considering the effect of extraction and grind, HCI is sure to be more effective in improving the physical pr operties of the SR.

(2) Confirming conditions for the acid treatment of the SR

In general, the polysaccharide components in plant tissues structurally firmly are integrated by the hydrophobic bond and the Van der waals force of intramolecular of the polysaccharide, each polysaccharide molecules and hydrogenic bond of the polysaccharide and protein. Correctly to illustrate this problem, soybean residue is treated in the solution of $\mathrm{HCl}, \mathrm{SDS}, \mathrm{NaOH},\left(\mathrm{NH}_{4}\right)_{2} \mathrm{C}_{2} \mathrm{O}_{4},\left(\mathrm{NH}_{4}\right)_{2} \mathrm{C}_{2} \mathrm{O}_{4},+\mathrm{SDS}$ and tested the changeon the extractability and degree of swelling.

Table 3. The extractability and degree of swelling of treated SR in different solution

\begin{tabular}{|l|c|c|c|c|c|}
\hline Section & $\begin{array}{c}0.5 \% \\
\left(\mathrm{NH}_{4}\right)_{2} \mathrm{C}_{2} \mathrm{O}_{4}\end{array}$ & $\begin{array}{c}0.1 \mathrm{M} \\
\mathrm{HCl}\end{array}$ & $\begin{array}{c}0.1 \mathrm{M} \\
\mathrm{NaOH}\end{array}$ & $\begin{array}{c}0.5 \% \\
\text { SDS }\end{array}$ & $\begin{array}{c}0.5 \%\left(\mathrm{NH}_{4}\right)_{2} \mathrm{C}_{2} \mathrm{O} \\
4,+0.5 \% \text { SDS }\end{array}$ \\
\hline Extractability,\% & $29.79 \pm 0.23^{\mathrm{a}}$ & $46.50 \pm 0.46^{\mathrm{a}}$ & $39.81 \pm 0.12^{\mathrm{b}}$ & $29.12 \pm 0.26^{\mathrm{a}}$ & $35.27 \pm 0.41^{\mathrm{b}}$ \\
\hline $\begin{array}{l}\text { Degree of swelling, } \mathrm{mL} / \\
\mathrm{g}\end{array}$ & $12.4 \pm 0.34^{\mathrm{b}}$ & $14.8 \pm 0.51^{\mathrm{b}}$ & $15.2 \pm 0.21^{\mathrm{a}}$ & $11.8 \pm 0.37^{\mathrm{b}}$ & $13.7 \pm 0.38^{\mathrm{a}}$ \\
\hline
\end{tabular}

※ Data with different small letters $(\mathrm{a} \curlyvee)$ in a column are significantly different at $p<0.05$ by Duncan's multiple range test.

As shown in Table 3, in the solution of $0.1 \mathrm{M} \mathrm{NaOH}$ the degree of swelling is bigest, but the extractability is sma ller than in other solution. Therefore $\mathrm{HCl}$ solution has the best effection in the brusting property on the bond o f gluciside and peptide. The results indicated that the SR treatment in $\mathrm{HCl}$ is brusted the polycation bonding of $\mathrm{SR}$, then the polysaccharide and protein is hydrolysed and producted its micro-substance.

(3) The change of particle size, shear stress $(\tau)$ and viscosity $\left(\eta_{a}\right)$ on the acidic grinding treatment The particle size of SR sample in this experiment is $474 \mu \mathrm{m}$, and this is coarse, is dryed again and grinding, but the particle size is still $337 \mu \mathrm{m}$ and coarse, then has no edible significant. In this experiment, observed the change of the particle size in the initial SR sample and treated SR sample.

Table 4. The change of particle size in the acidic grinding treatment

\begin{tabular}{|l|c|c|c|c|}
\hline Gample & 1 & 2 & 3 & 4 \\
\hline Initial SR $(\mu \mathrm{m})$ & & & & \\
\hline Treated SR $(\mu \mathrm{m})$ & $401 \pm 1.28^{\mathrm{d}}$ & $387 \pm 1.45^{\mathrm{c}}$ & $334 \pm 2.65^{\mathrm{b}}$ & $294 \pm 2.78^{\mathrm{a}}$ \\
\hline
\end{tabular}

※ Data with different small letters (a d) in a column are significantly different at $p<0.05$ by Duncan’s multiple range test. 
As shown table 4, in according to increase the grinding times number, the particle size of all sample is decreased. In initial SR sample, in according to increased the grinding times number, the change of it's particle size is not notable, but in treated SR sample is notable. In No. 3 grinding times, the particle size of treated SR is $55 \mu \mathrm{m}$ and is decreased than initial sample as $1 / 8$. The observed result on the shear stress and viscosity according to grinding times number is table 5 .

Table 5. The change of shear stress $(\tau)$ and viscosity $\left(\eta_{a}\right)$ on the acidic grinding treatment

\begin{tabular}{|c|c|c|c|c|c|}
\hline $\begin{array}{c}\text { Grinding times number } \\
\text { characteristics }\end{array}$ & 0 & 1 & 2 & 3 & 4 \\
\hline$\eta_{\mathrm{a}}(\mathrm{Pa} \cdot \mathrm{S})$ & $0.69 \pm 0.21^{\mathrm{d}}$ & $1.29 \pm 0.23^{\mathrm{c}}$ & $1.50 \pm 0.35^{\mathrm{b}}$ & $1.61 \pm 0.42^{\mathrm{b}}$ & $1.68 \pm 0.31^{\mathrm{a}}$ \\
\hline$\tau(\mathrm{Pa})$ & $11.74 \pm 0.48^{\mathrm{d}}$ & $21.94 \pm 0.47^{\mathrm{d}}$ & $25.52 \pm 0.38^{\mathrm{c}}$ & $27.39 \pm 0.23^{\mathrm{b}}$ & $28.58 \pm 0.41^{\mathrm{a}}$ \\
\hline
\end{tabular}

※ (Condition: speed $17.01 \mathrm{~s}^{-1}$, temperature $25^{\circ} \mathrm{C}$ )

※ Data with different small letters ( $\sim$ d) in a column are significantly different at $p<0.05$ by Duncan's multiple range test

As shown table 4, in according to increase the grinding times number, the shear stress and viscosity is rapidly $\mathrm{i}$ ncreased. The resulted indicated that the resistance on the external operation is increased as the acidic treatme $\mathrm{nt}$ and grinding, or the shear stress of SR is increased as 1.9 times and after No. 2 grinding times is increased as 2 times. The resulted indicated that improved the particle size and material property of SR as the acidic treatme $n t$ for the effect of extraction and grinding

(4) Confirming conditions for the acid treatment of the SR

The results in changes of the extractability according to the acid density and extract temperature are shown in Figure 1.

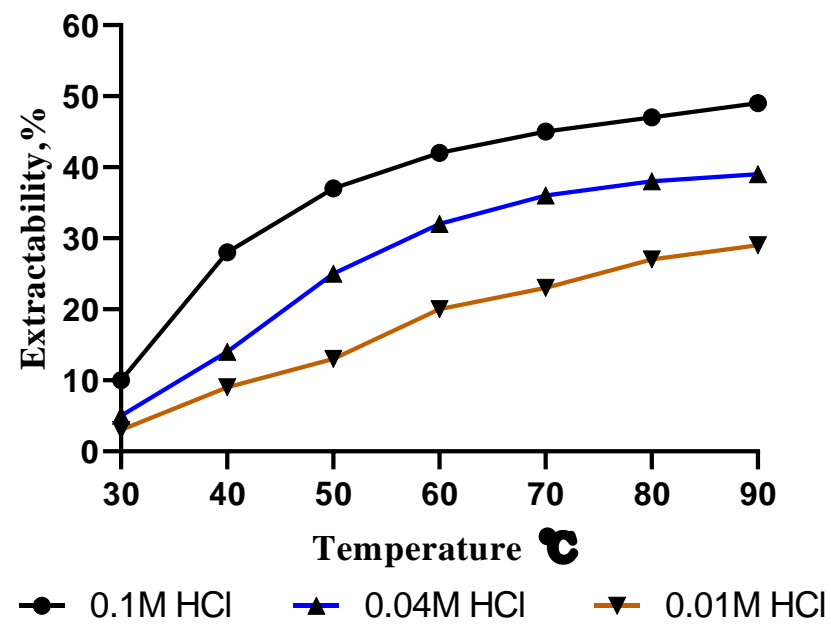

Figure 1 . Changes of the extractability according to the acid density and extract temperature

As shown in Figure 1, the extractability increased rapidly with the rise in acid density and extract temperature. The effect of the extract temperature shows that the temperature of above $50^{\circ} \mathrm{C}$ led to the rapid increase in extractability and the temperature of above $70^{\circ} \mathrm{C}$ led to only minor increase with the rise in the 
temperature(Except for $0.01 \mathrm{M} \mathrm{HCl}$ solvent test). The effect of the acid density shows that $0.01 \mathrm{M} \mathrm{HCl}$ solvent sample is lowest in extractability and from $0.04 \mathrm{M} \mathrm{HCl}$ solvent sample is highest in extractability. Based on the results in Figure1, the density of $\mathrm{HCl}$ solvent was fixed at $0.04 \sim 0.10 \mathrm{M}$, and the changes in extractability was examined according to the extract time at $70^{\circ} \mathrm{C}$. The result is as following Figure 2.

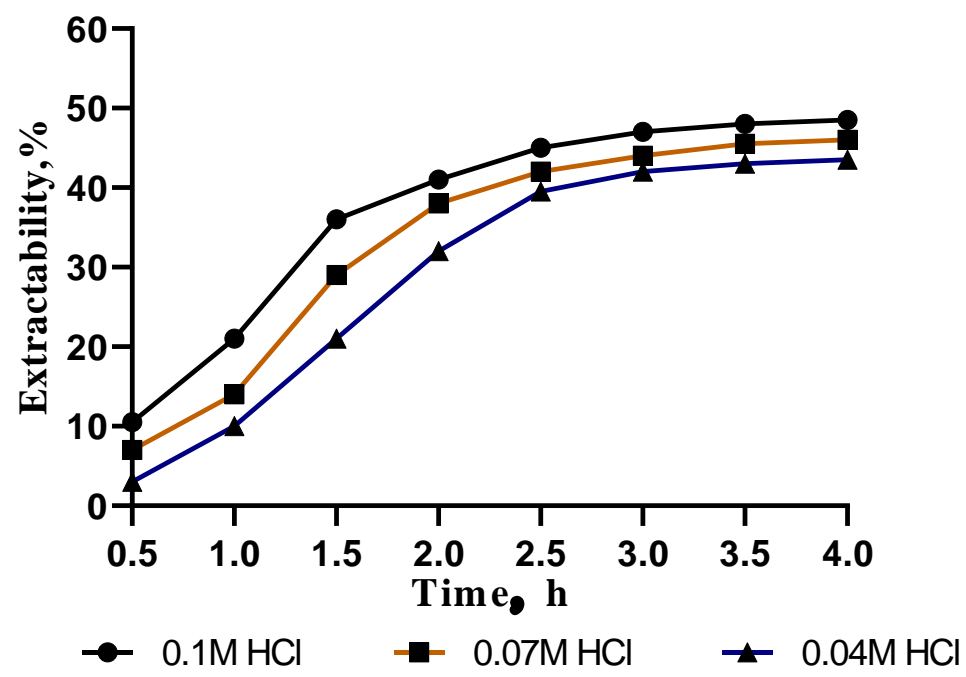

Figure 2. Changes in the extractability according to changes acid density and extract time

As shown in Figure 2, through the extract time got longer, the extractability rapid increase up to 2 hours and gr adual increase after it, and it showed greater changes in high acid density. Generally the extraction of notable c ompound in plant tissue using acid often causes extraction and separation at the same time. The wanted compo nent is SR polysaccharides, and both the extractability and polysaccharides separation must be considered. Ther efore extractability of micromolecule was examined in different acid density and extraction time and the result s were shown in Table 6.

Table 6. Changes in extractability of micromolecule in different acid density and extract time

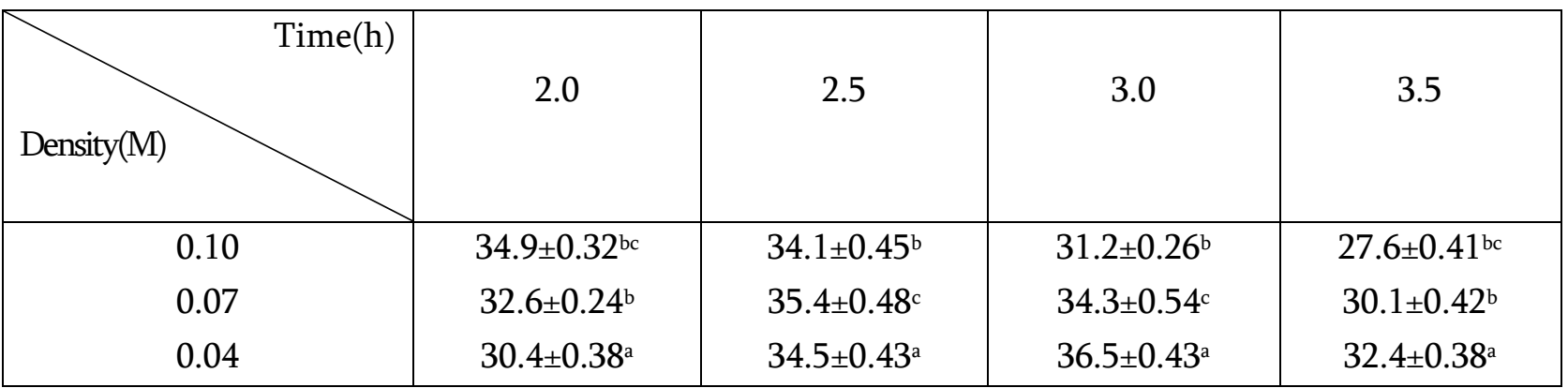

※xtraction time $70^{\circ} \mathrm{C}$

※ Data with different small letters $\left(\mathrm{a}^{\sim} \mathrm{c}\right)$ in a column are significantly different at $p<0.05$ by Duncan's multiple range test.

As shown in Table 6, extractability of micromolecule tended to increase with increasing of the extract time and decrease again. The experiment results in Table 6 shows the higher the acid density is and the longer the extract time is, the higher the extractability gets but the more active the separation of the polysaccharides gets. And the less the acid density was, the higher the maximum extractability of micromolecule got. Consequently, 
the extractability becomes increased to $34.9 \%$ in the $0.10 \mathrm{M} \mathrm{HCl}$ solution test tube, $35.4 \%$ in $0.07 \mathrm{M}$ one and $36.6 \%$ in $0.04 \mathrm{M}$ one. Based on the experiment results in Table 6 . The condition of the acid treatment of SR were fixed as follows: extract temperature $70^{\circ} \mathrm{C}$, acid density $0.04 \mathrm{M}$.

\subsection{The characteristics of crushed product of the SR acid}

(1) Characteristics of fluidity of the crushed product of the SR acid

The results of measuring the shearing stress in different shear rate of the crushed product of the acidic treated $\mathrm{S}$ $\mathrm{R}$ is shown in Figure 3.

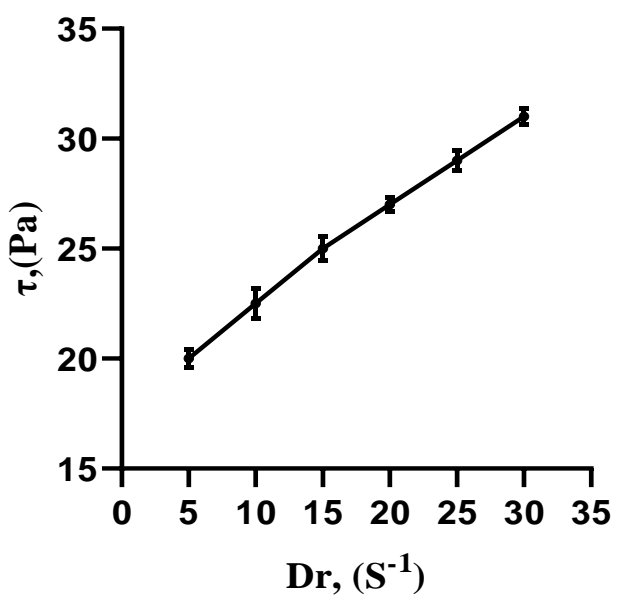

Figure 3. Changes in shearing stress of crushed product of the acidic treated SR in different shearing stress

As shown in the figure 3, the shearing stress $(\tau)$ upgraded linearly with an increase in amount of crushed SR an $\mathrm{d}$ sheer rate (Dr). The experiment of figure 3 resulted the fluidity equation of crushed product of the acidic trea ted SR

$$
\tau=18.17+0.50 \times \mathrm{Dr}, \mathrm{Pa}
$$

As shown in the fluidity equation of crushed product of the acidic treated SR, the crushed SR constitute Biham fluid of yield value $\left(\tau_{0}=18.17 \mathrm{~Pa}\right)$ and Biham viscosity $(\eta B=0.50 \mathrm{~Pa} \cdot S)$. Many foodstuffs like chocolate, tomato $s$ auce, mayonnaise and rich cream features Biham substance flex, as well as crushed SR.

(2) Dispersion and emulsification stability, and water and oil absorbing capacity

Examination result of dispersion and emulsification stability, and water and oil absorbing capacity of the crushe d product of the acidic treated SR is as follows.

Table 7. Dispersion and emulsification stability, and water and oil absorbing capacity of SR and the crushe d product of the acidic treated SR

\begin{tabular}{|c|c|c|c|c|c|}
\hline$x$ & $\mathrm{DS}, \%$ & $\mathrm{ES}, \%$ & $\begin{array}{c}\text { Water } \\
\text { absorbing ca } \\
\text { pacity } \\
\text { (WAC) } \\
\text { g/g }\end{array}$ & $\begin{array}{c}\text { Oil absorbing } \\
\text { capacity } \\
\text { (OAC) } \\
\text { g/g }\end{array}$ & $\begin{array}{l}\text { Emulsifying } \\
\text { liquid absorbe } \\
\text { d force } \\
\text { (ELAF) } \\
\text { g/g }\end{array}$ \\
\hline $\mathrm{SR}^{*}$ & $16.8 \pm 0.32^{\mathrm{a}}$ & $45.6 \pm 0.25^{a}$ & $4.3 \pm 0.36^{a}$ & $1.95 \pm 0.47^{a}$ & $2.26 \pm 0.41^{b}$ \\
\hline $\begin{array}{l}\text { Crushed product } \\
\text { of SR acid treatment }\end{array}$ & $84.2 \pm 0.43^{b}$ & $68.4 \pm 0.34^{b}$ & $5.4 \pm 0.48^{b}$ & $3.41 \pm 0.54^{b}$ & $5.54 \pm 0.37^{a}$ \\
\hline
\end{tabular}


※ *Third-round crushed product

※ Data with different small letters $(\mathrm{a}\urcorner)$ in a column are significantly different at $p<0.05$ by Duncan’s multiple range test.

As shown in the Table 7, dispersion stabilities (DS) of SR and the acidic treated SR are 16.8\%, 84.2\%, respectiv ely, in which DS of the acidic treated SR is about 5 times higher than that of SR. And emulsifying stability (ES) of the acidic treated SR is $68.4 \%$ which is 1.6 times higher than SR. SR are nearly a insolubility compound with little emulsifying feature. However, acid treatment increased its soluble component, creating new surfaces to $r$ emarkably upgrade emulsifying stability. The crushed product of SR acid treatment has little difference from th e SR in figures of water absorbing capacities (WAC) while the former is noticed to be increased in figures of oil absorbing capacities (OAC) and emulsifying liquid absorbed force (ELAF). We can normally say that the more pores in a particle, the higher in its OAC. The examination result in Table 7 shows that the acidic treatment pr ocess forms more pores in the crushed product of the acidic treated SR than SR.

\section{DISCUSSION}

Firstly, through this experiment, selected the medium; As shown table 2, during the treatment of $\mathrm{HCl}$ and $\mathrm{NaOH}$ the tissue structure of the SR is destroyed, which allows the extraction of some of its composites including polysaccharides and protein that is not extracted in water, and at the same time they are crushed into smaller pieces by the external mechanical knock, which increases the viscosity of the crushed product. As shown table 3, the particle size is changed to $474 \mu \mathrm{m}$ from $55 \mu \mathrm{m}$ after grinding treatment, then the viscosity of the sample is 2 times increased to 0.69 from 1.61 as shown table 4 .So when considering the effect of extraction and grind, HCI is sure to be more effective in improving the physical properties of the SR. Secondly, confirming conditions for the acid treatment of the SR; As shown figure 1, the effect of the extract temperature shows that the temperature of above $50^{\circ} \mathrm{C}$ led to the rapid increase in extractability and the temperature of above $70^{\circ} \mathrm{C}$ led to only minor increase with the rise in the temperature. (Except for $0.01 \mathrm{M} \mathrm{HCl}$ solvent test) The effect of the acid density shows that $0.01 \mathrm{M} \mathrm{HCl}$ solvent sample had significant low extractability and from $0.04 \mathrm{M} \mathrm{HCl}$ solvent sample it had significant increase in extractability. Consequently, the extraction rate becomes increased to $34.9 \%$ in the $0.10 \mathrm{M} \mathrm{HCl}$ solution test tube, $35.4 \%$ in $0.07 \mathrm{M}$ one and $36.6 \%$ in $0.04 \mathrm{M}$ one. The condition of the acid treatment of SR were fixed as follows: extraction temperature $70^{\circ} \mathrm{C}$, acid density $0.04 \mathrm{M}$. Thirdly, tested the characteristics of fluidity; As shown in the fluidity equation of crushed product of the acidic treated SR and table 7, the crushed SR constitute Biham fluid of yield value $\left(\tau_{\mathrm{o}}=18.17 \mathrm{~Pa}\right)$ and Biha-m viscosity $\left(\eta_{\mathrm{B}}=0\right.$. $50 \mathrm{~Pa} \cdot \mathrm{S})$. Many foodstuffs like chocolate, tomato sauce, mayonnaise and rich cream features Biham substance flex, as well as crushed SR. Through this content, determined that the method of this experiment is more significant than before.

\section{CONCLUSION}

Because soybean has rich nutrient component that $\mathrm{pr}$ otein, fiber, fat and carbohydrate and so on, people's $n$ eed level for the bean food is high, then which has led to the increase in the amount of SR, the by-products. Specially, a lot of scientist have a growing interest in $\mathrm{SR}$, because carbohydrate is rich in it. In this thesis, c onfirmed the method to improve the physical propert $y$ of SR as the method that extract the water-soluble $p$ olysaccharides and destroy the tissue of structure of $\mathrm{S}$ $\mathrm{R}$ and the study on the characteristics is carried out. F irstly, established the method and process system to e xtreact the water-soluble polysaccharides scientificall y. Secondly, selected the reasonable solution and cond ition of the treatment to destroy the tissue of SR's stru cture through this thesis. In here, confirmed that the reasonable solution is $\mathrm{HCl}$. Then the fluidity equation 
of crushed product of the acidic treated SR has the ch aracteristics of Biham fluid and confirmed the equatio $\mathrm{n}$ that is $\tau=18.17+0.50 \times \mathrm{Dr}$, Pa through this thesi s scientifically. Thirdly, the optimal condition for $\mathrm{HC}$ $\mathrm{L}$ treatment of SR is $70^{\circ} \mathrm{C}$ of temperature, 3 hours of e xtract time and $0.04 \mathrm{M}$ of density. The crushed produc $\mathrm{t}$ of the acidic treated SR is remarkably high in dispers ion stability, emulsifying stability and oil absorbing ca pacity.

\section{REFERENCES}

[1]. Ming-ChiTsai, Tuzz-YingSong, Ping-HsiaoShih, et al. Antioxidant properties of water-soluble polysaccharides from Antrodia cinnamomea in submerged culture [J] . Food Chemistry, 2007, 104(3): 1115-1122.

[2]. Y.Matsumuraa, M.Egamia, C.Satakea, et al. Inhibitory effects of peptide-bound polysaccharides on lipid oxidation in emulsions JFood Chemistry, 2003, 83(1): 107-119.

[3]. Takahiro Funami, Makoto Nakauma, Sakie Noda, et al . Effects of some anionic polysaccharides on the gelatinization and retrogradation behaviors of wheat starch: soybean-soluble polysaccharide and gum arabic

[J] . Food Hydrocolloids, 2008, 22(8):15281540.

[4]. Sachio Hayashi, Katsuhiro Matsuzaki, Toshikazu Kawahara, et al. Utilisation of soybean residue for the production of $\beta$ fructofuranosidase JBioresource Technology, 1992, 41(3):231-233.

[5]. Ya Wen, Meng Niu, Binjia Zhang, et al Structural characteristics and functional properties of rice bran dietary fiber modified by enzymatic and enzyme micronization treatmentsJLwt-Food, 2017, 75:344-351.

[6]. Tengxiang Lian, Jian Jin, Guanghua Wang, et al. The fate of soybean residue-carbon links to changes of bacterial community composition in
Mollisols differing in soil organic carbon, J] Soil Biology and Biochemistry, 2017,109; 50-58.

[7]. Z. Hromádková, A. Ebringerová, P. Valachovičb, et al. Ultrasound-assisted extraction of water-soluble polysaccharides from the roots of valerian (Valeriana oficinalis L.)JUltrasonics Sonochemistry, 2002, 9(1): 3744.

[8]. Yihua Jiang, Xinlong Jiang, et al. Response Surface Optimization of Microwave-assisted Extraction Conditions of anthocyanins from Black soybean hull, JApplied Mechanics and Materials, 2013, 395-396: 672-677.

[9]. Approved Methods AACC: 46-11A, Crude Protein-Improved Kjeldahl Method, Copper Catalyst Modification.

[10]. Approved Methods AACC: 30-10, Crude Fat in Flour, Bread, and Baked Cereal Products Not Containing Fruit.

[11]. Approved Methods AACC: 08-01 Ash-Basic Method.

[12]. Approved Methods AACC: 32-06 Total Dietary Fiber-Rapid Gravimetric Method.

[13]. Approved Methods AACC: 80-60 Determination of Reducing and Nonreducing Sugars.

[14]. Tatsuya Masuko, Akio Minami, Norimasa Iwasaki, et al. Carbohydrate analysis by a phenol-sulfuric acid method in microplate format, Analytical Biochemistry, 2005, 339(1); 69-72.

\section{Cite this article as :}

KwangChol Oh, SongLok Uh, BokShil Kim, NamChol Choe, YongChol Won, UnSuk Guak, SongIl Pak, "Study on the Manufacture and Feature of the Crushed Product of Acidic Treated Soybean Residue", International Journal of Scientific Research in Science, Engineering and Technology (IJSRSET), Online ISSN : 2394-4099, Print ISSN : 2395-1990, Volume 8 Issue 1, pp. 137-146, January-February 2021. Available at doi : https://doi.org/10.32628/IJSRSET218125 Journal URL : http://ijsrset.com/IJSRSET218125 